\title{
Use of health care services by people with substance use disorders in Belgium: a register-based cohort study
}

Luk Van Baelen ${ }^{1 *}$, Els Plettinckx ${ }^{1}$, Jérôme Antoine ${ }^{1}$, Karin De Ridder $^{1}$, Brecht Devleesschauwer ${ }^{1,2}$ and Lies Gremeaux ${ }^{1}$

\begin{abstract}
Background: The objective of the study was to describe the frequencies of health-care utilization by people with substance use disorder (SUD), including contacts with general practitioners (GP), psychiatrists, emergency departments (ED) and hospital admissions and to compare this frequency to the general population.

Methods: Data from the national register of people who were in treatment for SUD between 2011 and 2014 was linked to health care data from the Belgian health insurance $(N=30,905)$. Four comparators were matched on age, sex and place of residence to each subject in treatment for SUD $(N=123,620)$. Cases were further divided in five mutually exclusive categories based on the main SUD (opiates, crack/cocaine, stimulants, cannabis and alcohol). We calculated the average number of contacts with GP, psychiatrists and ED, and hospital admissions per person over a ten year period (2008-2017), computed descriptive statistics for each of the SUD and used negative binomial regression models to compare cases and comparators.

Results: Over the ten-year period, people in treatment for SUD overall had on average 60 GP contacts, 3.9 psychiatrist contacts, 7.8 visits to the ED, and 16 hospital admissions. Rate ratios, comparing cases and corresponding comparators, showed that people in treatment for SUD had on average 1.9 more contacts with a GP ( $95 \% \mathrm{Cl}$ 1.9-2.0), 7.4 more contacts with a psychiatrist ( $95 \%$ Cl 7.0-7.7), 4.2 more ED visits (95 \% Cl 4.2-4.3), and 6.4 more hospital admissions (95\% Cl 6.3-6.5).

Conclusions: The use of health services for people with SUD is between almost two (GP) and seven times (psychiatrist) higher than for comparators. People in treatment for alcohol use disorders use health care services more frequently than people in treatment for other SUD. The use of health services remained stable in the five years before and after the moment people with SUD entered into treatment for SUD. The higher use of primary health care services by people with SUD might indicate that they have higher health care needs than comparators.
\end{abstract}

Keywords: Substance Use Disorders, Health care services, Health care service providers, Belgium, Cohort study, Epidemiology

\footnotetext{
* Correspondence: luk.vanbaelen@sciensano.be

'Sciensano, Department of Epdemiology and public health, Rue Juliette Wytsmanstraat, 14, 1050 Brussels, Belgium

Full list of author information is available at the end of the article
}

(c) The Author(s). 2021 Open Access This article is licensed under a Creative Commons Attribution 4.0 International License, which permits use, sharing, adaptation, distribution and reproduction in any medium or format, as long as you give appropriate credit to the original author(s) and the source, provide a link to the Creative Commons licence, and indicate if changes were made. The images or other third party material in this article are included in the article's Creative Commons licence, unless indicated otherwise in a credit line to the material. If material is not included in the article's Creative Commons licence and your intended use is not permitted by statutory regulation or exceeds the permitted use, you will need to obtain permission directly from the copyright holder. To view a copy of this licence, visit http://creativecommons.org/licenses/by/4.0/ The Creative Commons Public Domain Dedication waiver (http://creativecommons.org/publicdomain/zero/1.0/) applies to the data made available in this article, unless otherwise stated in a credit line to the data. 


\section{Background}

People with substance use disorders (SUD) are known to have poor health outcomes and increased risk of premature death. In Belgium, previous research found that being in treatment for SUD increased all-cause mortality risk nearly elevenfold for users of illicit drugs, and sevenfold for users of licit drugs [1]. In 2017 in Belgium, alcohol was estimated to account for $5.3 \%$ of all deaths and $6.1 \%$ of the disability-adjusted life-years (DALYs) [2]. In the same year (2017), illicit drugs were estimated to contribute to $0.25 \%$ of all deaths and to $0.81 \%$ of the DALYs. People with SUD have a higher risk of contracting cancers, cardiovascular, respiratory and liver disorders $[3,4]$ or infectious diseases such as tuberculosis [5], hepatitis $C$ [6] or diseases due to the human immunodeficiency virus (HIV) [7], and also more oral health problems [8].

Notwithstanding these high needs, people with SUD face many obstacles when in need for general health care treatment: lack of financial means, lack of knowledge about the availability of help, lack of trust in treatment, and stigmatizing attitudes among health professionals [9-12]. For example, one of the reasons for the low number of people with SUD treated for Hepatitis C Virus (HCV) is some clinicians considering them as difficult to treat because of existing social and psychological barriers and concerns about reinfection [13-15]. However, recent studies in Belgium $[16,17]$ have shown that there is no significant difference in outcome between HCV treatment of people with SUD and the general population. Several other national and international studies have reported that treatment barriers not only exist in the case of infectious diseases such as hepatitis $\mathrm{C}$ or HIV [6, 7] but also for general health care [18, 19], hospital care $[18,20]$, dental health care [8], palliative care [21], and preventive measures such as contraception [22] or for access to pharmacies [18]. Although scientific literature on these obstacles is lacking for people with SUD in Belgium, there is no reason to believe that they face less barriers for these health problems than people in other parts of the world.

Because of these obstacles, previous studies have concluded that people with SUD heavily rely on emergency departments for general healthcare problems [23, 24]. A meta-analysis in 2019 revealed that people with SUD have on average 4.8 times more episodes in emergency departments than the general population [25]. The same review also identified several gaps in the evidence such as the fact that little is known about the health care use of people with cannabis use disorders, MDMA or amphetamine use disorders, powder cocaine use disorders, as well as the lack of knowledge about the use of primary health care by people with SUD [25]. It remains unclear whether the higher use of ED visits and hospitalizations are indeed the result of postponed care due to structural, financial and social obstacles, or if the needs for PWUD are generally much higher, which could also result in more frequent use of primary health care.

To address these gaps, the primary objective of this study is to describe the frequencies of health-care utilization by people with SUD, more specifically contacts with general practitioners (GP), psychiatrists, emergency departments (ED) and hospital admissions, for people with alcohol use disorders, cannabis use disorders, disorders related to the use of stimulants other than crack/cocaine, cocaine use disorders and opiate use disorders. The second objective is to compare the frequency of health-care utilization of these people to the general population in Belgium.

\section{Methods}

Data for the current study was generated through the linkage and matching of two existing Belgian national health and population registers: (1) the Belgian Treatment Demand Indicator database (TDI) with information on socio-demographic variables and substances for which treatment was sought at the start of the treatment episode for people in treatment for SUD, covering almost all specialized drug treatment centers and by around one third of the general or psychiatric hospitals [26], and (2) the InterMutualistic Agency database (IMA, [27]) with data on reimbursed health care services, gathered through the seven Belgian health insurance agencies. The data that was used from this database consists of contacts with general practitioners, psychiatrists, ED and admissions to the hospital, and spanned a period between 1 January 2008 and 31 December 2017. The full IMA-database covers $99 \%$ of the people living in Belgium, as health care insurance is mandatory [28].

The Belgian National Identification Number (NIN) was used to link both databases. All patients registered in TDI with a NIN who started a treatment for SUD between 2011 and 2014 and who could be identified in the IMA database were considered eligible subjects for this study $(n=30,905)$. For those with multiple episodes the first treatment episode in TDI was selected, in line with the TDI-IMA protocol [28]. Cases were further divided in five mutually exclusive categories: people in treatment for opiate use disorders (some of which were also in treatment for other substances), people in treatment for crack/cocaine use disorders who were not in treatment for opiates, people in treatment for stimulant use disorders (mainly MDMA and amphetamines) who were not in treatment for opiates or crack/cocaine, people in treatment for cannabis use disorders with or without alcohol use disorders who were not in treatment for opiates, crack/cocaine or stimulants, and people in treatment for only alcohol use disorders. 
Furthermore, there were 3,198 people in treatment for other substances, who were excluded from the analysis, which gives a total of 27,707 cases.

A group of comparators who had not been in treatment for SUD between 2011 and 2014 was selected from the general population through the IMA database [28]. Four comparators were matched on age, sex and municipality of residence to each case in treatment for SUD. Sex and age were considered to be basic matching variables. The potential confounding of municipality of residence is related to regional differences in health care regulation, health care seeking and access to specialized medical health care for SUD as well as other differences that might be present, for instance socio-economic status of the patients by region.

For people with SUD as a whole as well as for each of the five patient categories and the corresponding comparators and for men and women separately, we calculated the median and average number of contacts with primary care physicians, psychiatrists and ED, and hospital admissions per person over the ten year period. We computed descriptive statistics for each of these groups and used negative binomial regression models to compare cases and comparators. This analysis models the log of the expected count (i.e., number of visits) as a linear function of cases versus comparators. The coefficients obtained were exponentiated to get rate ratios (with corresponding $95 \%$ confidence intervals). For the graphical representation of the average use of each outcome variable data were recalibrated towards the day people with SUD entered into treatment. Graphs represent the results of the outcome variable five years before and five years after this day. In this way, they illustrate the evolution over time per month for each category of patients and corresponding comparators.

Data analysis was done using SAS software version 9.3 (SAS Institute Inc., Cary, NC). The reporting of this study conforms to the STROBE guidelines [29].

\section{Results}

As shown in Table 1, almost one in three cases was in treatment for alcohol use disorders only, one in five was in treatment for cannabis or opiate use disorders, whereas $14 \%$ was in treatment for cocaine use disorders and $8.6 \%$ for stimulant use disorders.

People in treatment for alcohol use disorders were older, were more likely to have been in treatment for SUD before and relied mainly on inpatient services. People in treatment for disorders related to street drugs were younger and most often supported by outpatient services.

Over the ten-year period 2008-2017, people in treatment for SUD overall had on average 60 GP contacts, 3.9 psychiatrist contacts, 7.8 visits to the ED, and 16 hospital admissions (Table 2).
Rate ratios, comparing cases and corresponding comparators, showed that people in treatment for SUD had on average 1.9 more contacts with a GP $(95 \%$ CI 1.9 2.0), 7.4 more contacts with a psychiatrist (95\% CI 7.07.7), 4.2 more ED visits (95\% CI 4.2-4.3), and 6.4 more hospital admissions (95\% CI 6.3-6.5) (Table 3).

Rate ratios per SUD category ranged for GP contacts between 1.6 (cannabis, $95 \% \mathrm{CI} 1.6-1.6$ ) and 2.6 (opiates, $95 \%$ CI 2.5-2.7), for psychiatrist contacts between 5.6 (cannabis, 95 \%CI 4.9-6.3) and 7.7 (alcohol, $95 \%$ CI 7.18.3), for contacts with ED between 2.8 (cannabis, $95 \% \mathrm{CI}$ 2.7-2.8) and 5.7 (alcohol, $95 \% \mathrm{CI} 5.6-5.9$ ), and for hospital admissions between 4.6 (opiates, $95 \%$ CI 4.4-4.8) and 7.6 (alcohol, $95 \%$ CI 7.3-7.8).

Women with SUD were using health care services more than men, with rate ratios ranging between 1.1 (ED, $95 \% \mathrm{CI} 1.1-1.1$ ) and 1.7 (hospital admissions, $95 \%$ CI 1.6-1.7).

Figure 1 illustrates the monthly proportion of people in treatment for SUD in contact with GP for each category of SUD and their comparators. It reflects the data of Table 2 as monthly averages, e.g. people with alcohol use disorders have over the 120 months period on average 65 contacts with a GP, which give an average of approximately 0.5 contacts per month per person. Figures 2, 3 and 4 give a similar representation of the proportion of people in treatment for SUD and comparators in contact with psychiatrists, the ED and by hospital admissions, respectively.

\section{Discussion}

Use of health care services by people with SUD is high. Our results for ED and hospitalizations episodes are in line with the results of previous studies [25]. At the same time, our study gives a better understanding of the number of contacts with general practitioners by people with SUD. People in treatment for SUD have between 1.6 and 1.9 times more contacts with a GP than their comparators, except for people in treatment for opiate use disorders who have on average 2.6 times more contacts with their GP than their respective comparators. The reason for this higher frequency might be that many of them are on substitution treatment for which they have to consult a GP. For all other considered health service providers, people with alcohol use disorders had more frequent contacts than people with disorders related to street drugs and the comparators. This last observation is in contrast to findings from a previous study where people with alcohol use disorders were found to use less health care services than the general population [30].

Overall, people with SUD had a higher use of primary care than acute health care, which is in line with findings from the few number of studies who reported on this 
Table 1 Descriptive statistics people in treatment for substance use disorder by main product in Belgium (2011-2014)

\begin{tabular}{|c|c|c|c|c|c|c|c|}
\hline & & & opiates & crack/cocaine & stimulants & cannabis & alcohol \\
\hline \multirow[t]{4}{*}{ Sex $(N$ missing $=9)$} & Men & $N$ & 4502 & 3420 & 1998 & 4924 & 6207 \\
\hline & & $\%$ & $79.1 \%$ & $80.9 \%$ & $74.8 \%$ & $85.3 \%$ & $66.5 \%$ \\
\hline & Women & $N$ & 1188 & 807 & 675 & 852 & 3125 \\
\hline & & $\%$ & $20.9 \%$ & $19.1 \%$ & $25.3 \%$ & $14.8 \%$ & $33.5 \%$ \\
\hline \multirow[t]{12}{*}{ Age $(\mathrm{N}$ missing $=2365)$} & $<20$ & $N$ & 68 & 177 & 308 & 1363 & 26 \\
\hline & & $\%$ & $1.2 \%$ & $4.4 \%$ & $12.3 \%$ & $25.8 \%$ & $0.3 \%$ \\
\hline & $20-29$ & $\mathrm{~N}$ & 1568 & 1737 & 1038 & 2236 & 388 \\
\hline & & $\%$ & $28.5 \%$ & $43.4 \%$ & $41.4 \%$ & $42.3 \%$ & $4.7 \%$ \\
\hline & $30-39$ & $\mathrm{~N}$ & 2153 & 1516 & 839 & 1125 & 1322 \\
\hline & & $\%$ & $39.2 \%$ & $37.9 \%$ & $33.4 \%$ & $21.3 \%$ & $16.0 \%$ \\
\hline & $40-49$ & $N$ & 1380 & 480 & 260 & 435 & 2690 \\
\hline & & $\%$ & $25.1 \%$ & $12.0 \%$ & $10.4 \%$ & $8.2 \%$ & $32.6 \%$ \\
\hline & $50-59$ & $N$ & 299 & 83 & 59 & 114 & 2686 \\
\hline & & $\%$ & $5.4 \%$ & $2.1 \%$ & $2.4 \%$ & $2.2 \%$ & $32.5 \%$ \\
\hline & $>60$ & $N$ & 25 & 10 & 6 & 11 & 1147 \\
\hline & & $\%$ & $0.5 \%$ & $0.2 \%$ & $0.2 \%$ & $0.2 \%$ & $13.9 \%$ \\
\hline \multirow[t]{6}{*}{ Region (N missing $=0$ ) } & Flanders & $\mathrm{N}$ & 3096 & 3345 & 2604 & 4785 & 6298 \\
\hline & & $\%$ & $54.4 \%$ & $79.1 \%$ & $97.4 \%$ & $82.8 \%$ & $67.5 \%$ \\
\hline & Wallonia & $\mathrm{N}$ & 1815 & 602 & 43 & 768 & 2591 \\
\hline & & $\%$ & $31.9 \%$ & $14.2 \%$ & $1.6 \%$ & $13.3 \%$ & $27.8 \%$ \\
\hline & Brussels & $\mathrm{N}$ & 780 & 280 & 26 & 227 & 447 \\
\hline & & $\%$ & $13.7 \%$ & $6.6 \%$ & $1.0 \%$ & $3.9 \%$ & $4.8 \%$ \\
\hline \multirow[t]{4}{*}{ In treatment before $(\mathrm{N}$ missing $=1768)$} & No & $\mathrm{N}$ & 965 & 1969 & 1215 & 3547 & 3295 \\
\hline & & $\%$ & $19.3 \%$ & $49.1 \%$ & $48.6 \%$ & $63.4 \%$ & $36.6 \%$ \\
\hline & Yes & $\mathrm{N}$ & 4035 & 2042 & 1283 & 2045 & 5709 \\
\hline & & $\%$ & $80.7 \%$ & $50.9 \%$ & $51.4 \%$ & $36.6 \%$ & $63.4 \%$ \\
\hline \multirow[t]{4}{*}{ Type treatment setting $(\mathrm{N}$ missing $=0$ ) } & Inpatient & $\mathrm{N}$ & 2341 & 1675 & 761 & 1506 & 7918 \\
\hline & & $\%$ & $41.1 \%$ & $39.6 \%$ & $28.5 \%$ & $26.1 \%$ & $84.8 \%$ \\
\hline & Outpatient & $\mathrm{N}$ & 3350 & 2552 & 1912 & 4274 & 1418 \\
\hline & & $\%$ & $58.9 \%$ & $60.4 \%$ & $71.5 \%$ & $73.9 \%$ & $15.2 \%$ \\
\hline \multirow[t]{2}{*}{ Total } & & $N$ & 5691 & 4227 & 2673 & 5780 & 9336 \\
\hline & & $\%$ & $18.4 \%$ & $13.7 \%$ & $8.6 \%$ & $18.7 \%$ & $30.2 \%$ \\
\hline
\end{tabular}

[31, 32]. Compared to the comparators, the differences in use of health services between people in treatment for disorders related to cannabis, stimulants and crack/cocaine are minimal for contacts with the GP, and not significant for hospitalizations and contacts with psychiatrists. Only people in treatment for cannabis use disorders have significantly less contacts with the ED than the comparators compared to people with disorders related to stimulants and crack/cocaine.

Interestingly, as shown by the Figs. 1, 2, 3 and 4, there is little difference in the number of contacts with the specific health service providers over time within each category of SUD. Indeed, the use of health services remains quite stable in the five years before and after the moment people with SUD entered into treatment. Of course, this does not provide insights in individual variation over time, but it remains interesting to see that this level of health care use was that stable. We could not find other studies to support or contradict this finding.

One reason for the high use of general health services might be that the data is based on the first episode in TDI between 2011 and 2014, with between $36.6 \%$ (cannabis) and $80.7 \%$ (opiates) of the cases who had been already in treatment for SUD before, meaning that they might have had already serious substance use related 
Table 2 Median and mean number of contacts/episodes with health provider/service (standard deviation (sd)) per 10 person-years for people in treatment for substance use disorders between 2011 and 2014 and their comparators in Belgium, overall, by substance and by sex (2008-2017)

\begin{tabular}{|c|c|c|c|c|c|c|c|c|c|c|c|c|c|c|}
\hline & & \multirow[b]{2}{*}{$\mathbf{n}$} & \multicolumn{3}{|c|}{ Contacts with GP } & \multicolumn{3}{|c|}{ Contacts with psychiatrist } & \multicolumn{3}{|c|}{ Contacts with ED ${ }^{a}$} & \multicolumn{3}{|c|}{ Hospital admissions } \\
\hline & & & median & mean & sd & median & mean & sd & median & mean & sd & median & mean & sd \\
\hline \multirow[t]{2}{*}{ overall } & control & 123620 & 23 & 30.8 & 33.3 & 0 & 0.5 & 1.2 & 1 & 1.9 & 2.9 & 1 & 2.5 & 9.4 \\
\hline & case & 30905 & 43 & 59.9 & 68.4 & 0 & 3.9 & 10.8 & 5 & 7.8 & 11.9 & 6 & 16.0 & 30.8 \\
\hline \multirow[t]{2}{*}{ opiates } & control & 22764 & 19 & 26.1 & 29.4 & 0 & 0.6 & 4.5 & 1 & 2.1 & 3.3 & 1 & 2.2 & 9.7 \\
\hline & case & 5691 & 44 & 68.5 & 82.7 & 0 & 3.9 & 14.1 & 5 & 7.9 & 10.8 & 5 & 10.1 & 21.4 \\
\hline \multirow[t]{2}{*}{ cocaine/crack } & control & 16908 & 20 & 26.7 & 27.9 & 0 & 0.4 & 3.7 & 1 & 1.9 & 2.8 & 1 & 2.1 & 10.0 \\
\hline & case & 4227 & 36 & 47.0 & 49.1 & 0 & 2.7 & 7.8 & 5 & 7.0 & 8.4 & 4 & 10.6 & 23.1 \\
\hline \multirow[t]{2}{*}{ stimulants } & control & 10692 & 23 & 29.1 & 27.5 & 0 & 0.4 & 3.1 & 1 & 1.8 & 2.6 & 1 & 2.2 & 8.7 \\
\hline & case & 2673 & 40 & 53.3 & 55.7 & 0 & 2.5 & 8.0 & 4 & 5.8 & 6.5 & 4 & 11.9 & 25.0 \\
\hline \multirow[t]{2}{*}{ cannabis } & control & 23120 & 19 & 24.8 & 25.2 & 0 & 0.4 & 2.9 & 1 & 2.0 & 2.9 & 1 & 1.8 & 6.7 \\
\hline & case & 5780 & 31 & 39.6 & 43.1 & 0 & 2.1 & 6.5 & 3 & 5.6 & 8.3 & 3 & 8.9 & 21.9 \\
\hline \multirow[t]{2}{*}{ alcohol } & control & 37344 & 29 & 38.0 & 39.3 & 0 & 0.7 & 5.1 & 1 & 1.6 & 2.7 & 1 & 3.2 & 10.4 \\
\hline & case & 9336 & 51 & 64.7 & 62.7 & 1 & 5.0 & 11.2 & 6 & 9.1 & 14.2 & 12 & 24.2 & 38.4 \\
\hline \multirow[t]{2}{*}{ women } & control & 32268 & 33 & 41.6 & 40.6 & 0 & 0.7 & 4.4 & 1 & 1.7 & 3.0 & 2 & 3.4 & 9.5 \\
\hline & case & 8067 & 62 & 81.9 & 84.1 & 1 & 4.9 & 11.8 & 6 & 8.6 & 12.7 & 11 & 22.5 & 13.3 \\
\hline \multirow[t]{2}{*}{ men } & control & 91316 & 20 & 26.9 & 29.3 & 0 & 0.5 & 4.1 & 1 & 1.9 & 2.9 & 1 & 2.2 & 9.4 \\
\hline & case & 22829 & 37 & 52.1 & 60.1 & 0 & 3.5 & 10.4 & 5 & 7.6 & 11.6 & 5 & 13.7 & 27.8 \\
\hline
\end{tabular}

${ }^{a} G P$ general practitioner, ED emergency department

and general health care problems before the day on which they were registered in TDI. We also acknowledge the fact that the proportion of people with hospital admissions in the months after start of treatment for alcohol cases (Fig. 4) shows a slower decline than for other substance categories, although at this time we cannot provide a good explanation for this.

A previous study concluded that the higher use of health care services by PWUD, compared to comparators from the general population, reflects the greater need for treatment, but that it does not necessarily represent good health-care access and that this might reflect a pattern where primary and preventative health care is poor and PWUD rely mainly on unplanned health care [25]. The current study gives a more nuanced picture. Indeed, PWUD make more use of ED and are more admitted to hospitals, but also the use of GPs is significantly higher than for comparators. This higher use of primary health care could underline the presence of high needs, as does the substantial higher use of psychiatric care. At the same time, the current study cannot conclude that access for PWUD is sufficient or that existing care services answer the needs of PWUD, since we only analyzed the use of health care and not outcome of care. For instance, postponing to seek and receive health care is likely to increase the risk of developing complications

Table 3 Rate ratios (RR) (with standard error (SE) and $95 \%$ confidence interval (CI)) of use of health provider/service for people in treatment for substance use disorders between 2011 and 2014 versus comparators in Belgium, overall, by substance and by sex (2008-2017)

\begin{tabular}{|c|c|c|c|c|c|c|c|c|c|c|c|c|}
\hline & \multicolumn{3}{|c|}{ Contacts with GPa } & \multicolumn{3}{|c|}{ Contacts with psychiatrist } & \multicolumn{3}{|c|}{ Contacts with ED ${ }^{a}$} & \multicolumn{3}{|c|}{ Hospital admissions } \\
\hline & $\overline{R R}$ & $S E$ & $95 \% \mathrm{Cl}$ & $\overline{R R}$ & $S E$ & $95 \% \mathrm{Cl}$ & $\overline{R R}$ & SE & $95 \% \mathrm{Cl}$ & $R R$ & $S E$ & $95 \% \mathrm{Cl}$ \\
\hline Overall & 1.9 & 0.01 & $1.9-2.0$ & 7.4 & 0.17 & $7.0-7.7$ & 4.2 & 0.03 & $4.2-4.3$ & 6.4 & 0.06 & $6.3-6.5$ \\
\hline Opiates & 2.6 & 0.04 & $2.5-2.7$ & 6.7 & 0.40 & $5.9-7.5$ & 3.7 & 0.06 & $3.5-3.8$ & 4.6 & 0.10 & $4.4-4.8$ \\
\hline Cocaine & 1.8 & 0.03 & $1.7-1.8$ & 6.5 & 0.40 & $5.7-7.4$ & 3.6 & 0.07 & $3.5-3.8$ & 5.0 & 0.12 & $4.8-5.3$ \\
\hline Stimulants & 1.8 & 0.03 & $1.8-1.9$ & 7.0 & 0.61 & $5.9-8.3$ & 3.3 & 0.08 & $3.1-3.5$ & 5.3 & 0.16 & $5.0-5.6$ \\
\hline Cannabis & 1.6 & 0.02 & $1.6-1.6$ & 5.6 & 0.30 & $4.9-6.3$ & 2.8 & 0.05 & $2.7-2.8$ & 4.9 & 0.10 & $4.7-5.1$ \\
\hline Alcohol & 1.7 & 0.02 & $1.7-1.7$ & 7.7 & 0.30 & $7.1-8.3$ & 5.7 & 0.05 & $5.6-5.9$ & 7.6 & 0.11 & $7.3-7.8$ \\
\hline Women (vs. men) & 1.6 & 0.02 & $1.5-1.6$ & 1.4 & 0.04 & $1.3-1.5$ & 1.1 & 0.02 & $1.1-1.2$ & 1.7 & 0.03 & $1.6-1.7$ \\
\hline
\end{tabular}

${ }^{\mathrm{a}} \mathrm{GP}$ general practitioner, ED emergency department 


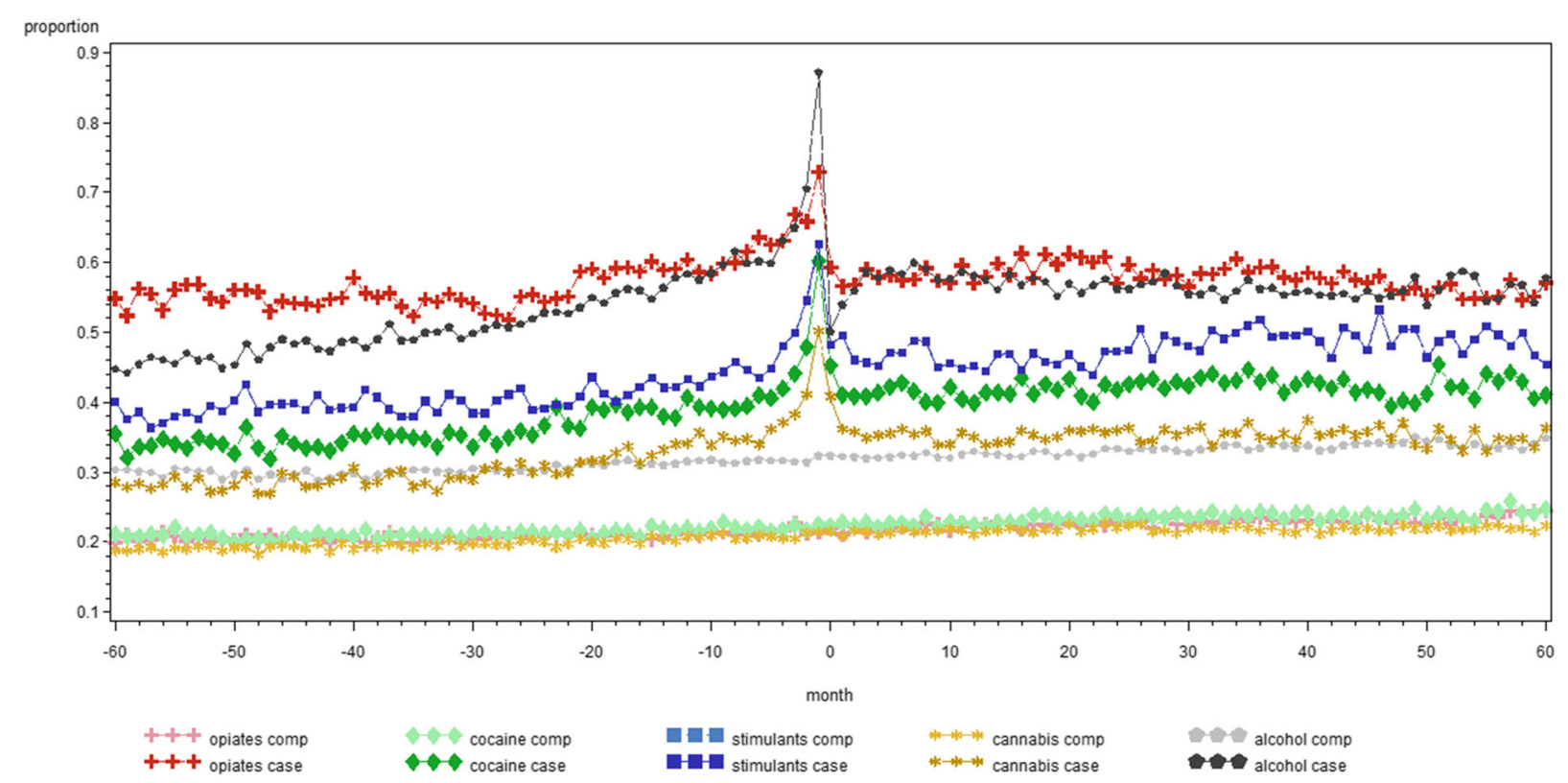

Fig. 1 Monthly proportion of people in treatment for substance use disorders between 2011 and 2014 and comparators in contact with general practitioner in the five years before and after the day of start treatment, by substance in Belgium (2008-2017)

[33]. Even if PWUD attend more often than comparators a GP, it might still be that they wait much longer to seek help, which might result in more intense use of health care services.

The current study has several limitations, some of which have already been mentioned in previous articles $[1,6,28]$. Three out of four episodes in TDI are registered with a NIN. This means that for one quarter of all episodes it was impossible to identify the person with SUD and to extract their data from the IMA-database. People who are registered without NIN are known to be more in treatment in a psychiatric unit of a general hospital, in treatment for opiates, in treatment in Wallonia and to be non-Belgian [34], but as shown by a previous study, there is little evidence that patient characteristics have a major impact on the registration with a NIN [34].

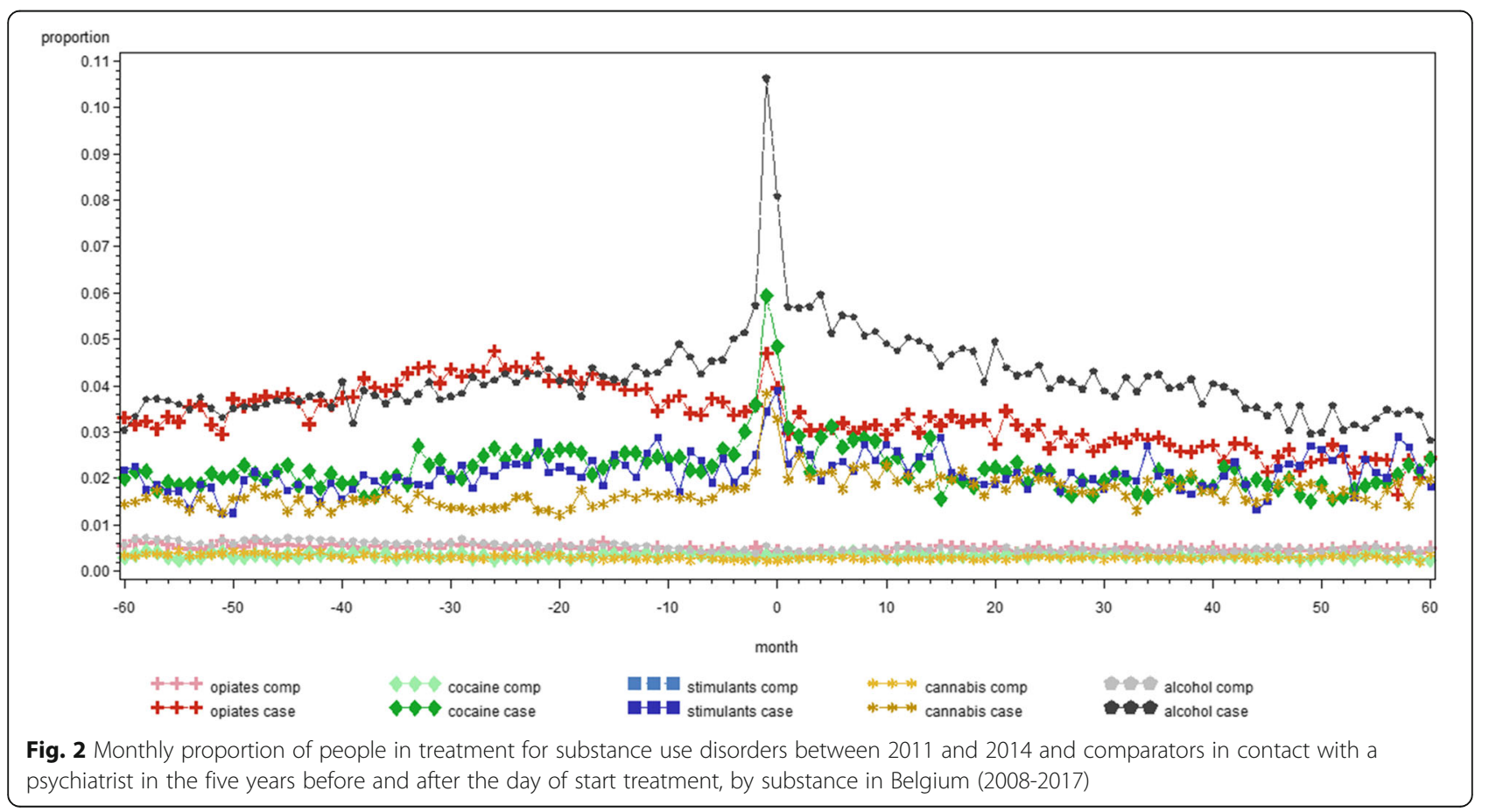




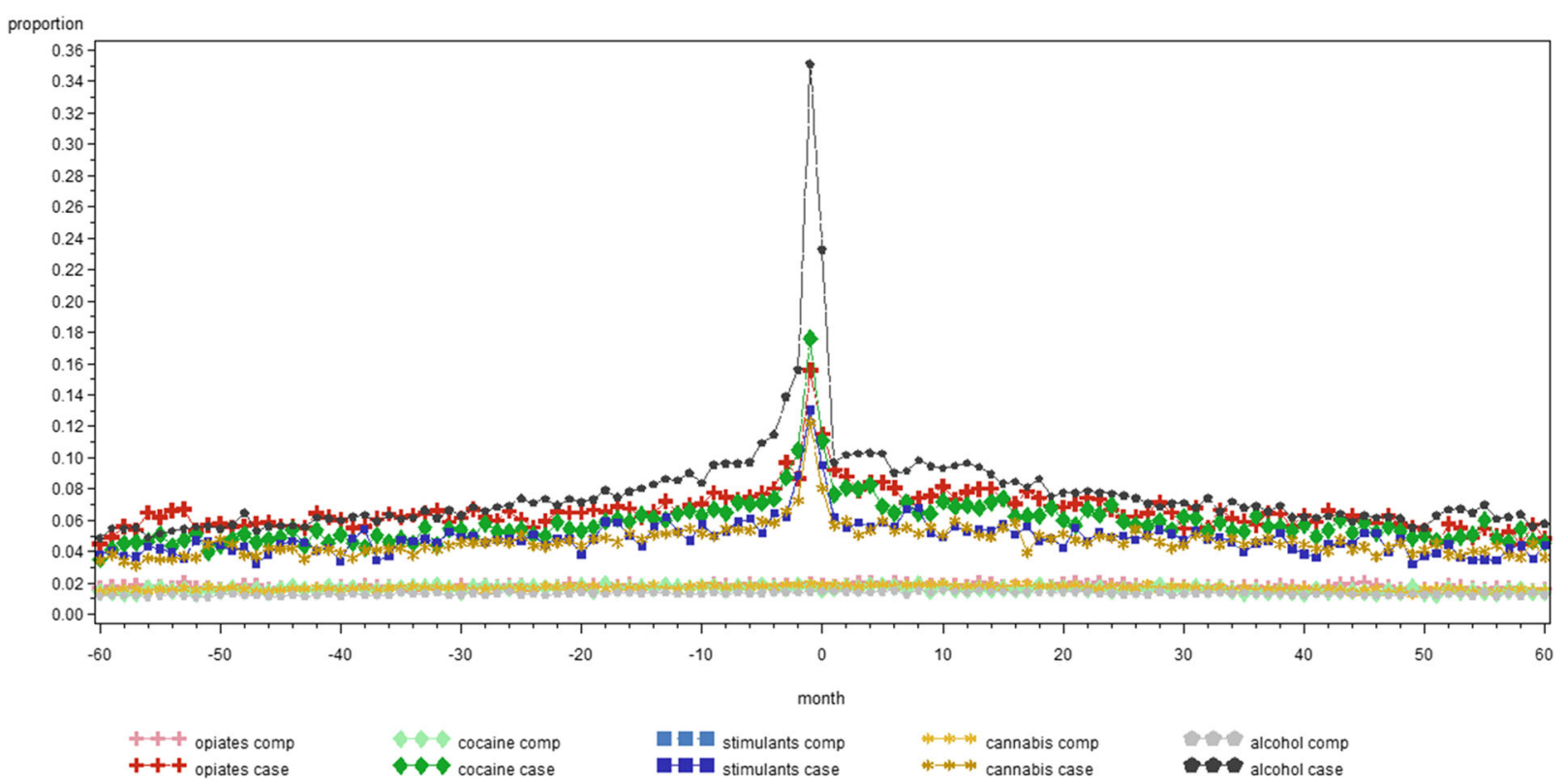

Fig. 3 Monthly proportion of people in treatment for substance use disorders between 2011 and 2014 and comparators in contact with emergency department in the five years before and after the day of start treatment, by substance in Belgium (2008-2017)

Moreover, outreach services and harm reduction initiatives are not covered by TDI, nor are GPs who are considered to play a major role in detecting and managing SUD directly [26]. This means that people with SUD who are only treated by GPs are not included in the database. However, for all people registered in TDI, data about their consultations to GPs are registered in IMA. As a result the exact denominator of all people who are in treatment for SUD in Belgium is unknown, but the proportion of them who are registered in TDI can be understood as the large majority. Further research will look into this denominator. Because health insurance is mandatory in Belgium, for almost all people who are registered in TDI with a NIN, data are available in IMA. As such, the reported results give a reliable understanding of the use of services for general healthcare

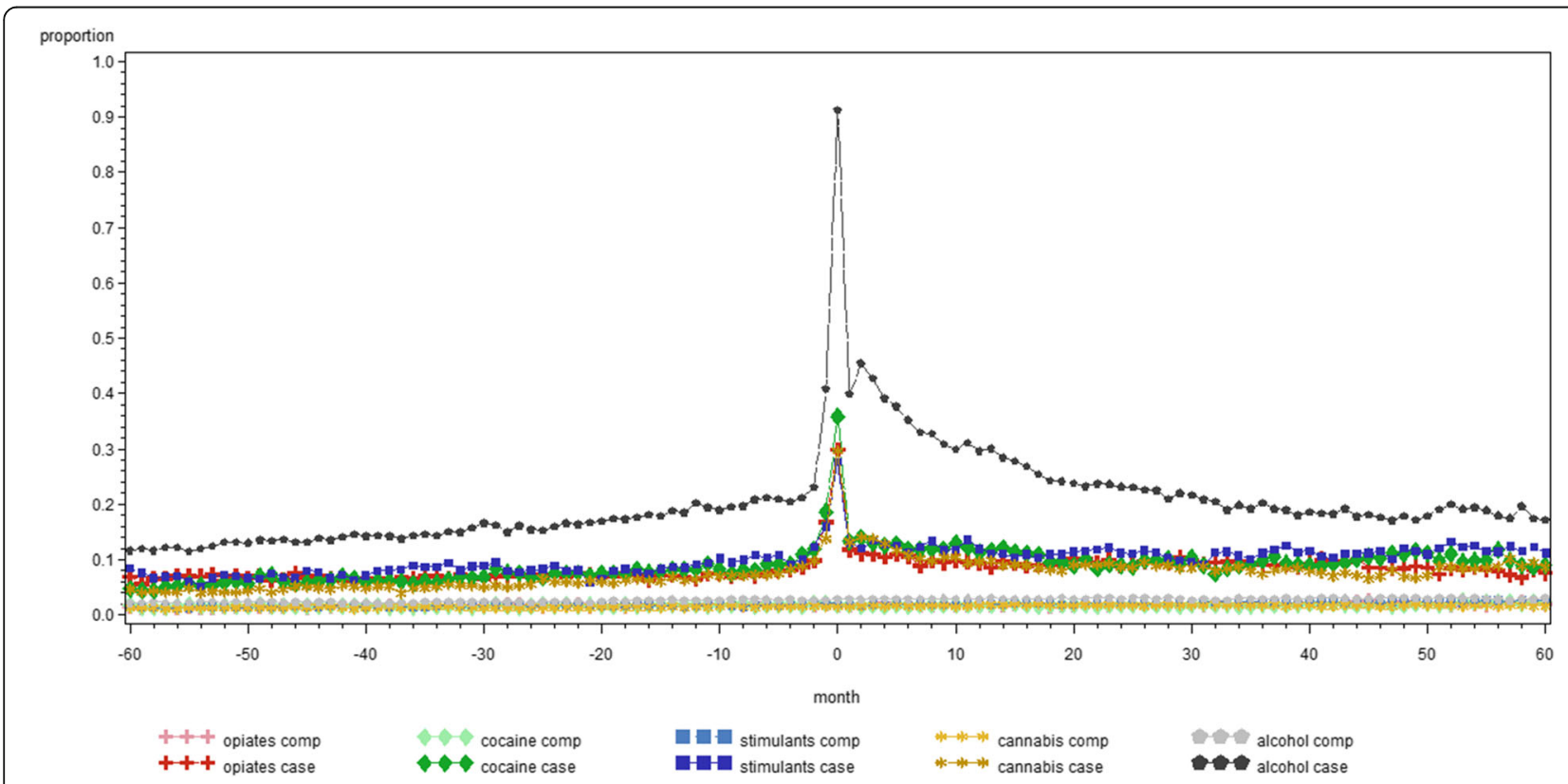

Fig. 4 Monthly proportion of people in treatment for substance used disorders between 2011 and 2014 and comparators with hospital admissions in the five years before and after the day of start treatment, by substance in Belgium (2008-2017) 
problems by people with SUD in Belgium who are registered in TDI with a NIN.

Finally, the use of register data for a vast and diversified group of people in treatment for SUD allows a better understanding of the number of contacts with health care service providers. However, the relatively limited evolution over time, and the fact that almost $60 \%$ of the cases had been in specialized treatment for SUD before, supports the idea that the development of SUD is a long-term process. Further research should thus take a longer time period into consideration to describe earlier phases in the use of general health care services leading to specialized treatment of SUD.

\section{Conclusions}

People with SUD go almost twice as often to the GP as comparators and more than seven times more often to the psychiatrist. They are also more than six times more frequently admitted to the hospital than comparators. People in treatment for alcohol use disorders make significantly more use of health services and health service providers than people in treatment for disorders related to street drugs. The use of health services remains quite stable in the five years before and after the moment people with SUD entered into treatment for their SUD.

\begin{abstract}
Abbreviations
TDI: Treatment Demand Indicator; IMA: InterMutualistisch Agentschap; SUD: Substance use disorder; GP: General practitioner; ED: The emergency departments; Cl: Confidence interval; DALY: Disability-adjusted life-years; HIV: Human immunodeficiency virus; HCV: Hepatitis C Virus; MDMA: 3,4Methyl enedioxy methamphetamine; NIN: National Identification Number
\end{abstract}

\section{Acknowledgements}

None.

\section{Authors' contributions}

LVB was responsible for conceptualization, analysis, methodology and writing the original draft, EP was responsible for validation and reviewing the manuscript, JA was responsible for the TDI data collection, KDR was responsible for conceptualization, methodology, validation and reviewing the manuscript, BDV was involved in the conceptualization, the formal analysis and reviewing the manuscript, LG was involved in the project administration and the critical revision of the manuscript. All authors read and approved the final manuscript.

\section{Funding}

This study received no specific grant from any funding agency in the public, commercial or not-for-profit sectors.

\section{Availability of data and materials}

The full dataset of this study is not available due to restricted access to the IMA database.

\section{Declarations}

\section{Ethics approval and consent to participate}

The project was approved by the Belgian Privacy Commission (SCSZG/15/ 033). IMA adheres to the Program Law of 24/12/2002, articles 278-281. The Belgian TDI protocol adheres to the European protocol and the Belgian privacy legislation, as described by Antoine et al. [26].

\section{Consent for publication}

Not applicable.

\section{Competing interests}

The authors declare that they do not have any conflicts of interest to disclose.

\section{Author details}

${ }^{1}$ Sciensano, Department of Epdemiology and public health, Rue Juliette Wytsmanstraat, 14, 1050 Brussels, Belgium. ${ }^{2}$ Department of Veterinary Public Health and Food Safety, Ghent University, Merelbeke, Belgium.

Received: 8 January 2021 Accepted: 24 May 2021

Published online: 23 June 2021

\section{References}

1. Van Baelen L, Antoine J, De Ridder K, et al. All-cause mortality rate of people in treatment for substance use disorders in Belgium: A registerbased cohort study. Journal of Substance Use. 2019;24:481-6. https://doi. org/10.1080/14659891.2019.1604841.

2. GBD 2017 Risk Factor Collaborators. Global, regional, and national comparative risk assessment of 84 behavioural, environmental and occupational, and metabolic risks or clusters of risks for 195 countries and territories, 1990-2017: a systematic analysis for the Global Burden of Disease Study 2017. Lancet. 2018;392:1923-94. https://doi.org/10.1016/S0140-6736(1 8)32225-6.

3. Degenhardt L, Larney S, Randall D, et al. Causes of death in a cohort treated for opioid dependence between 1985 and 2005. Addiction. 2004. https:// onlinelibrary.wiley.com/doi/abs/10.1111/add.12337.

4. Degenhardt L, Bucello C, Mathers B, et al. Mortality among regular or dependent users of heroin and other opioids: a systematic review and meta-analysis of cohort studies. Addiction. 2011;106:32-51. https://doi.org/1 0.1111/j.1360-0443.2010.03140.x.

5. Millet J-P, Moreno A, Fina $L$, et al. Factors that influence current tuberculosis epidemiology. Eur Spine J. 2013;22 Suppl 4:539-48. https://doi.org/10.1007/ s00586-012-2334-8.

6. Van Baelen L, Antoine J, De Ridder K, et al. Diagnostic hepatitis C testing of people in treatment for substance use disorders in Belgium between 2011 and 2014: a cross-sectional study. Acta Gastroenterol Belg. 2019;82:35-42.

7. Kamarulzaman A, Altice FL. Challenges in managing HIV in people who use drugs. Curr Opin Infect Dis. 2015;28:10-6. https://doi.org/10.1097/QCO. 0000000000000125

8. Sheridan J, Aggleton M, Carson T. Dental health and access to dental treatment: a comparison of drug users and non-drug users attending community pharmacies. Br Dent J. 2001;191:453-7. https://doi.org/10.1038/ sj.bdj.4801206.

9. van Boekel LC, Brouwers EPM, van Weeghel J, et al. Stigma among health professionals towards patients with substance use disorders and its consequences for healthcare delivery: Systematic review. Drug Alcohol Depend. 2013;131:23-35

10. Digiusto $E$, Treloar C. Equity of access to treatment, and barriers to treatment for illicit drug use in Australia. Addiction. 2007;102:958-69. https://doi.org/10.1111/j.1360-0443.2007.01842.x.

11. Mojtabai R, Olfson M, Mechanic D. Perceived need and help-seeking in adults with mood, anxiety, or substance use disorders. Arch Gen Psychiatry. 2002;59:77-84. https://doi.org/10.1001/archpsyc.59.1.77.

12. Morrisson A, Elliott L, Gruer L. Injecting-related harm and treatment-seeking behaviour among injecting drug users. Addiction. 2006;92:1349-52. https:// doi.org/10.1111/j.1360-0443.1997.tb02853.x.

13. Foster GR. Injecting drug users with chronic hepatitis C: should they be offered antiviral therapy? Addiction. 2008;103:1412-3.

14. Higgs P, Sacks-Davis R, Gold J, et al. Barriers to receiving hepatitis C treatment for people who inject drugs: Myths and evidence. Hepatitis Monthly. 2011;11:513-8.

15. Martin NK, Vickerman P, Miners A, et al. Cost-effectiveness of hepatitis C virus antiviral treatment for injection drug user populations. Hepatology 2012;55:49-57.

16. Bielen R, Moreno C, Van Vlierberghe H, et al. Belgian experience with direct acting antivirals in people who inject drugs. Drug Alcohol Depend. 2017; 177:214-20

17. Robaeys G, Christensen S, Lucidarme D, et al. Chronic Hepatitis C Treatment in Patients with Drug Injection History: Findings of the INTEGRATE Prospective, Observational Study. Infectious Diseases Therapy. 2017;6:265-75. 
18. Neale J, Tompkins C, Sheard L. Barriers to accessing generic health and social care services: a qualitative study of injecting drug users. Health Soc Care Community. 2008;16:147-54. https://doi.org/10.1111/j.1365-2524.2007. 00739.x.

19. Stephens KA, West II, Hallgren KA, et al. Service utilization and chronic condition outcomes among primary care patients with substance use disorders and co-occurring chronic conditions. J Subst Abuse Treat. 2020; 112S:49-55. https://doi.org/10.1016/j.jsat.2020.02.008.

20. Chan Carusone S, Guta A, Robinson S, et al. "Maybe if I stop the drugs, then maybe they'd care?"- - hospital care experiences of people who use drugs. Harm Reduction Journal. 2019;16:16. https:/doi.org/10.1186/s12954-019-0285-7.

21. Hudson BF, Flemming K, Shulman C, et al. Challenges to access and provision of palliative care for people who are homeless: a systematic review of qualitative research. BMC Palliative Care. 2016;15:96. https://doi. org/10.1186/s12904-016-0168-6.

22. Olsen A, Banwell C, Madden A. Contraception, punishment and women who use drugs. BMC Women's Health. 2014;14:5. https://doi.org/10.1186/14 72-6874-14-5.

23. Bahorik AL, Satre DD, Kline-Simon AH, et al. Alcohol, marijuana, and opioid use disorders: 5-Year patterns and characteristics of emergency department encounters. Subst Abus. 2018;39:59-68. https://doi.org/10.1080/08897077.2 017.1356789.

24. Sanjuan PM, Rice SL, Witkiewitz K, et al. Alcohol, tobacco, and drug use among emergency department patients. Drug Alcohol Depend. 2014;138: 32-8. https://doi.org/10.1016/j.drugalcdep.2014.01.025.

25. Lewer $D$, Freer J, King $E$, et al. Frequency of health-care utilization by adults who use illicit drugs: a systematic review and meta-analysis Addiction. Published Online First: 9 November. 2019. https://doi.org/1 0.1111 /add.14892

26. Antoine J, De Ridder K, Plettinckx E, et al. Treatment for substance use disorders: the Belgian Treatment Demand Indicator registration protocol. Archives of Public Health. 2016;74:27.

27. IMA. IMA Population Database. Published Online First. 4 October 2017. http://www.aim-ima.be/Data-Populatie-53_(Accessed 17 Jun 2020).

28. Van Baelen L, De Ridder K, Antoine J, et al. Longitudinal pharmacoepidemiological and health services research for substance users in treatment: protocol of the Belgian TDI-IMA linkage. Arch Public Health 2018;76. https://doi.org/10.1186/s13690-017-0249-x.

29. Vandenbroucke JP, von Elm E, Altman DG, et al. Strengthening the Reporting of Observational Studies in Epidemiology (STROBE): Explanation and Elaboration. PLoS Medicine. 2007;4:e297.

30. Zarkin GA, Bray JW, Babor TF, et al. Alcohol Drinking Patterns and Health Care Utilization in a Managed Care Organization. Health Serv Res. 2004;39: 553-70. https://doi.org/10.1111/j.1475-6773.2004.00244.x.

31. Darke S, Marel C, Ross J, et al. Health Service Utilization Among Heroin Users: 11-Year Follow-up of the Australian Treatment Outcome Study Cohort. Addictive Disorders Their Treatment. 2015;14:159-66. https://doi. org/10.1097/ADT.0000000000000069.

32. Lintzeris $N$, Rivas $C$, Monds LA, et al. Substance use, health status and service utilisation of older clients attending specialist drug and alcohol services. Drug Alcohol Rev. 2016;35:223-31. https://doi.org/10.1111/dar.12266.

33. Onyeka IN, Beynon CM, Ronkainen $\mathrm{K}$, et al. Hospitalization in a Cohort Seeking Treatment for Illicit Drug Use in Finland. J Subst Abuse Treat. 2015; 53:64-70.

34. Antoine J, Renard F. Registration of treatment demands for substance use disorders in Belgium: Why are some clients registered anonymously? Lisbon: 2017. https://workspaces.wiv-isp.be/tdi/Documenten\%20voor\%20TDIRegistra tie/Use\%20of\%20NISS\%20poster.pdf. Accesed 9 Jun 2021.

\section{Publisher's Note}

Springer Nature remains neutral with regard to jurisdictional claims in published maps and institutional affiliations.

Ready to submit your research? Choose BMC and benefit from:

- fast, convenient online submission

- thorough peer review by experienced researchers in your field

- rapid publication on acceptance

- support for research data, including large and complex data types

- gold Open Access which fosters wider collaboration and increased citations

- maximum visibility for your research: over $100 \mathrm{M}$ website views per year

At BMC, research is always in progress.

Learn more biomedcentral.com/submissions 